\title{
A Study on Patient Perceived Service Quality in a Tertiary Care Teaching Hospital
}

\author{
${ }^{1}$ Dr. Basava Malleswara Rao V, ${ }^{2}$ Dr.N.Satyanarayana, \\ ${ }^{I}$ Resident, Department of Hospital Administration, Nizam's Institute of Medical Sciences, Hyderabad, India \\ ${ }^{2}$ Professor and Head, Department of Hospital Administration, Nizam's Institute of Medical Sciences, \\ Hyderabad, India
}

\section{Introduction:}

Health service organizations assume some responsibility for the health of the population they serve and for demonstrating performance results. Global competition in health care is forcing many organizations to improve the quality of the health care they deliver. Clients are asking for and expecting more accountability on how organizations deliver health care and at what cost. The quality of healthcare has been a major problem in many Countries for many years. Finding a definition, methods of evaluation, monitoring and improvement have been the major problems that researchers and healthcare practitioners have had to investigate over the years.

A review of qualitative studies highlighted that in most studies patients defined quality as "patient centred care" and that quality would include having physical and emotional needs met, having individualised care as well as being involved in their care and decision making of care. The review also highlighted the importance of medical personnel who respect, listen to patients and anticipate their needs. Patients also viewed the protection of their privacy and confidentiality as important among others (Sofaer $\mathrm{S}$ and K. Firminger). ${ }^{1}$

Patient-perception of health care quality is critical to the success of a healthcare organization because of their influence on patient satisfaction and hospital profitability. Patients demand more information than ever and do not hesitate to switch to other health care providers if they don't obtain satisfaction (Ramsaran - Fowdar $\mathrm{R})^{2}$

There is growing evidence to suggest that perceived quality is the single most important variable influencing consumers' perception of value and that this, in turn, affects their intentions to purchase products or services. Service quality has also become recognized as a driver of corporate marketing and financial performance ${ }^{3}$. The organisations are supposed to measure the customer perceived service quality from time to time to provide better services to the customer. This holds true even in Health care organisations.

This research focuses on the patient perceived service quality in tertiary care teaching hospital. This information can be used to improve the service quality and patient satisfaction by improving the specific areas.

\section{Aims:}

1.) To study the patient perceived service quality in the hospital.

2.) To study the patient expectations of a hospital service.

3.) To study the patient perceptions of the hospital service received.

4.) To study the association between patient overall satisfaction and service quality.

The objectives of research are three fold.

\section{Objectives:}

1.) To measure any existing gaps between patient's perceptions and expectations.

2.) To measure any existing gaps between employee perceptions and expectations.

3.) To measure overall patient satisfaction and service quality dimensions.

The study is being conducted based on the Parasuraman et al, SERVQUAL model and is rooted in Donabedian's structure, process and outcome in healthcare organisations. In this framework the patient satisfaction is being used as the outcome of patient's perception of how care is received, the structure is refers to the physical facilities and personnel, and the process relates to the physical facilities and personnel, and the process relates to the functional aspects of quality, as the research is based on the patients perspective.

The SERVQUAL method was deemed fit to measure the quality as it would measure the expectations of the patients as well as provide feedback as to their perception of the service received. Also, based on the notion that patients are often unable to accurately evaluate the technical quality of care; the research focuses on the functional quality - how is the service delivery, which is considered the primary determinant of the patient ${ }^{\text {‘ }} \mathrm{s}$ quality $^{85}$. 


\section{Study Setting}

The research was conducted at a Tertiary Care Teaching hospital; the main referral hospital in the states of Andhra Pradesh and Telangana and was chosen for convenience, and it being the most attended facility in the country.

Questionnaire was developed based on the SERVQUAL measure for evaluating services. The permission to use SERVQUAL was obtained from the authors Parasuraman, A., Zeithaml, V.A. and Berry, L.L ${ }^{4}$.

SERVQUAL was developed to measure service quality in organizations and the scale was and tested across four service environments: banking, credit card services, repair and maintenance long distance telephone services and was adapted to hospital services by Babakus \& Mangold ${ }^{5}$. The data was collected using generic SERVQUAL questionnaire modified by Babakus \& Mangold to suit the hospital context (see questionnaire in appendix 1). The questionnaire included 15 paired questions and an overall rating scale. Each item was rated on a five -point likert scale anchored at the numeral 1 with the verbal statement __Strongly Disagree" and at the numeral 5 with the verbal statement __Strongly Agree.“"

\section{Sample (size and technique)}

The sample size was selected using online sample size calculator Raosoft Inc . The margin of accepted error was taken as $5 \%$ and confidence level of $95 \%$. The results indicated that sample size of at-least 300 would be required. A total 320 questionnaires were distributed to patients who received services at N.I.M.S. between periods November 2013 to March 2014.The questionnaires were distributed through systematic random sampling. These questionnaires were representative of the ratio of the patient flow of the outpatient, inpatient and emergency departments which will be 24:2:1 respectively on each day. A total of 80 questionnaires were distributed to N.I.M.S. employees of the hospital from April 2014 to May 2014, in a effort to make comparison between employees and patients. The sample was drawn from employees of the hospital who themselves had been patients at the hospital.

\section{Data Collection}

The patient's questionnaire was collected November 2013 to March 2014, at the N.I.M.S. It involved the distribution of 320 self administered survey questions, distributed at various key points of service delivery at the hospital, emergency department, outpatient department and the inpatient services of the hospitals, a total of 300 questionnaires were returned.

80 Employee questionnaires were distributed from April 2014 to May 2014, by the hospital. A total of 72 questionnaires were returned. An overall response rate of $90 \%$ response rate was achieved. Although both samples were collected at different time frame the data is considered consistent enough for comparison purposes as there was no significant changes in management policy within the time difference.

\section{Data Profile}

In this research, questionnaires were distributed to two groups, patients and staff of the hospital. The analysis consisted of data collected from 300 patient results, and 72 staff members.

Table 1: Department visited by Patient Respondents $n=300$

\begin{tabular}{lcc}
\hline Department & Frequency & Percentage \\
\hline Outpatient & 146 & $48 \%$ \\
Inpatient & 90 & $30 \%$ \\
Emergency & 66 & $22 \%$ \\
\hline
\end{tabular}

As illustrated in Table $1.48 \%$ or 146 of the respondents were drawn from patient who visited the outpatient department, $22 \%$ or 66 respondents from the Emergency department and $30 \%$ or 90 respondents drawn from the patients who were admitted to the hospital.

Table 2: Staff Respondents and Non respondents by Category $n=72$

\begin{tabular}{lllll}
\hline Staff Category & Respondents & Percentage & $\begin{array}{l}\text { Non- } \\
\text { Respondents }\end{array}$ & Percentage \\
\hline Doctor & 8 & $11 \%$ & 2 & $25 \%$ \\
Nurse & 14 & $21 \%$ & 1 & $12.5 \%$ \\
Administrative & 24 & $34 \%$ & 0 & $0 \%$ \\
Laboratory & 6 & $7 \%$ & 1 & $12.5 \%$ \\
Pharmacist & 4 & $5 \%$ & 1 & $12.5 \%$ \\
Auxiliary & 16 & $22 \%$ & 3 & $37.5 \%$ \\
\hline
\end{tabular}


Respondents from the staff was drawn from six categories, with the largest representation from administrative staff which had a total of 24 or $34 \%$ of staff respondents, followed by auxiliary workers who comprised $22 \%$ or a total of 16 respondents, nurses with $21 \%$ or 14 respondents, physicians with $11 \%$ or a total of 8 respondents, and $7 \%$ or 6 and $5 \%$ or 4 for laboratory and pharmacist, see table 4.2 . About $37.5 \%$ of the nonrespondents represented the auxiliary staff category, other categories with non respondents in include Doctors with $25 \%$ and nurses with $12.5 \%$. Both pharmacists and laboratory staff had $12.5 \%$ non-response rates.

Administrative staff had $100 \%$ response rates.

\section{Service Quality Results}

This section provides an analysis of the SERVQUAL questionnaire. Table four presents the summary statistics for patients ${ }^{6}$ expectations and perceptions. As illustrated expectation scores among the dimensions ranged from 1 to 5 , with assurance and responsiveness gaining minimum scores of 1 , while in all dimensions the maximum expectation score was gained was 5 . The highest mean expectation score among the dimension was received by assurance with 4.62 , while the lowest was received by tangibles with 4.47 . Standard deviations ranged from as low as 0.551 assurance to a high of 0.621 empathy; tangibles, reliability and responsiveness with standard deviations of $0.926,0.937,0.969$ respectively.

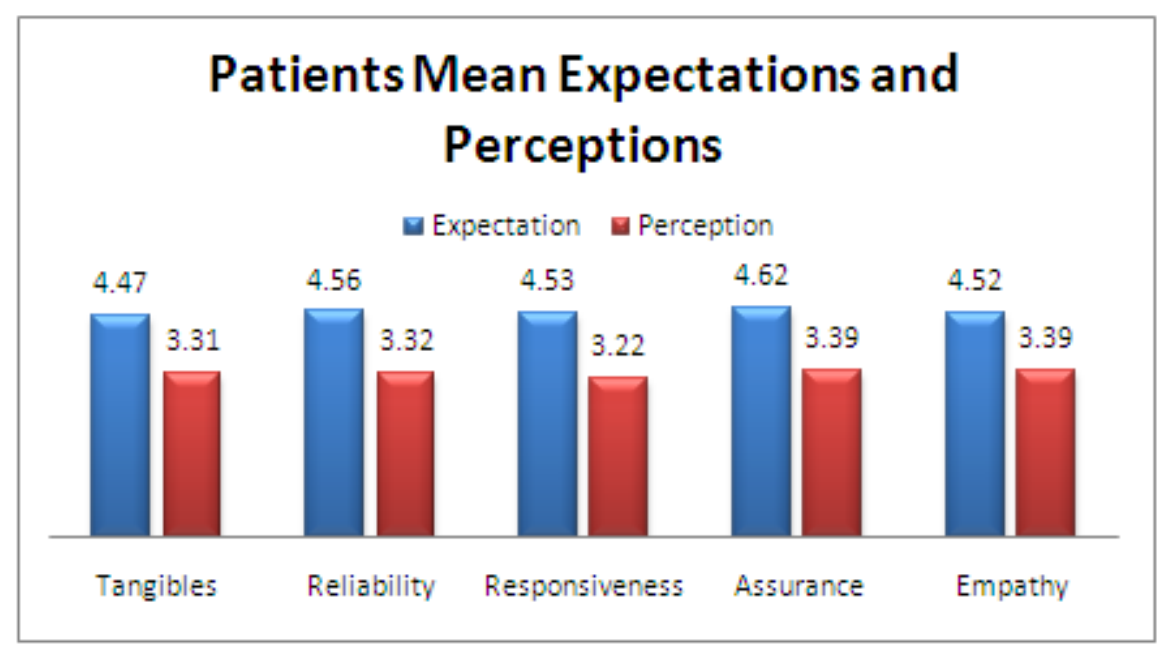

Table 3: SERVQUAL Gap 5: Patients' Perception - Patients' Expectation, rank and paired difference t-statistics

\begin{tabular}{|c|c|c|c|c|c|c|}
\hline Service Quality Attribute: & $\begin{array}{c}\text { Mean } \\
\text { Perception }\end{array}$ & $\begin{array}{c}\text { Mean } \\
\text { Expectation }\end{array}$ & $\begin{array}{l}\text { SERVQUAL } \\
\text { Score }\end{array}$ & Rank & $\mathrm{T}$ & Sig. \\
\hline Tangibles & 3.31 & 4.47 & -1.17 & II & -17.832 & 0.000 \\
\hline Up to date equipment & 3.03 & 4.37 & -1.34 & 14 & & \\
\hline $\begin{array}{l}\text { Visually appealing Physical } \\
\text { facilities }\end{array}$ & 3.45 & 4.50 & -1.06 & 1 & & \\
\hline Neat hospital employees & 3.45 & 4.55 & -1.10 & 2 & & \\
\hline Reliability & 3.32 & 4.56 & -1.25 & IV & -19.737 & 0.000 \\
\hline Timely services as promised & 3.16 & 4.50 & -1.34 & 13 & & \\
\hline $\begin{array}{l}\text { Sympathetic and reassuring } \\
\text { employees }\end{array}$ & 3.41 & 4.62 & -1.21 & 7 & & \\
\hline Accurate billing & 3.39 & 4.57 & -1.19 & 6 & & \\
\hline Responsiveness & 3.22 & 4.53 & -1.31 & V & -19.498 & 0.000 \\
\hline $\begin{array}{l}\text { Tell patients when services will } \\
\text { be performed }\end{array}$ & 3.22 & 4.45 & -1.23 & 8 & & \\
\hline Prompt services & 3.17 & 4.46 & -1.29 & 11 & & \\
\hline Willingness to help patients & 3.28 & 4.68 & -1.40 & 15 & & \\
\hline Assurance & 3.39 & 4.62 & -1.24 & III & -19.929 & 0.000 \\
\hline $\begin{array}{l}\text { Feel safe in interaction with } \\
\text { hospital employees }\end{array}$ & 3.33 & 4.65 & -1.32 & 12 & & \\
\hline Knowledgeable employees & 3.54 & 4.66 & -1.12 & 3 & & \\
\hline Polite employees & 3.37 & 4.62 & -1.26 & 10 & & \\
\hline Adequate support from employers & 3.31 & 4.56 & -1.25 & 9 & & \\
\hline Empathy & 3.39 & 4.52 & -1.14 & I & -17.107 & 0.000 \\
\hline $\begin{array}{l}\text { Personal attention from } \\
\text { employees }\end{array}$ & 3.32 & 4.45 & -1.13 & 4 & & \\
\hline $\begin{array}{l}\text { Patient's best interest at heart } \\
\text { Overall Score }=-1.32 \mathrm{t}=-21.23 \text { sig } 0.000\end{array}$ & 3.45 & 4.60 & -1.15 & 5 & & \\
\hline
\end{tabular}



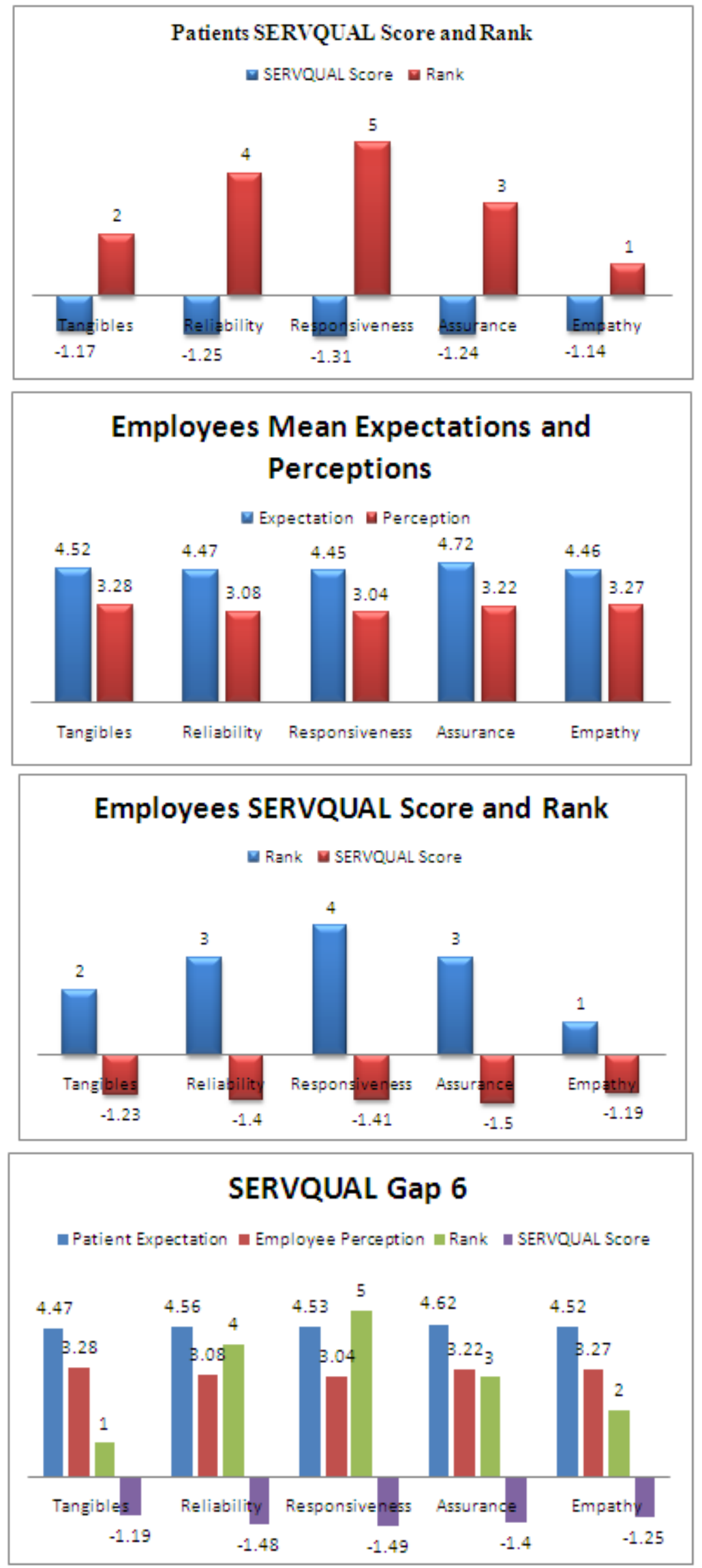


\section{Overall Satisfaction}

The overall satisfaction with services received at NIMS was generally satisfactory as $83 \%$ of respondents indicating a satisfactory or higher score as illustrated in table and Figure with a mean of 3.25 (SD 0.80 ). Only $18 \%$ returned an unsatisfactory or very poor rating.

Table 4: Respondent Overall Satisfaction with Services received at NIMS

\begin{tabular}{lllll}
\hline Overall Satisfaction & Patients $\mathrm{n}=300$ & \multicolumn{3}{c}{ Staff $=72$} \\
& Frequency & $\%$ & Frequency & $\%$ \\
\hline Very poor & 4 & $2 \%$ & 0 & $0 \%$ \\
Unsatisfactory & 52 & $18 \%$ & 6 & $10 \%$ \\
Satisfactory & 120 & $40 \%$ & 43 & $59 \%$ \\
Good & 109 & $37 \%$ & 23 & $31 \%$ \\
Excellent & 15 & $5 \%$ & 0 & $0 \%$ \\
\hline
\end{tabular}

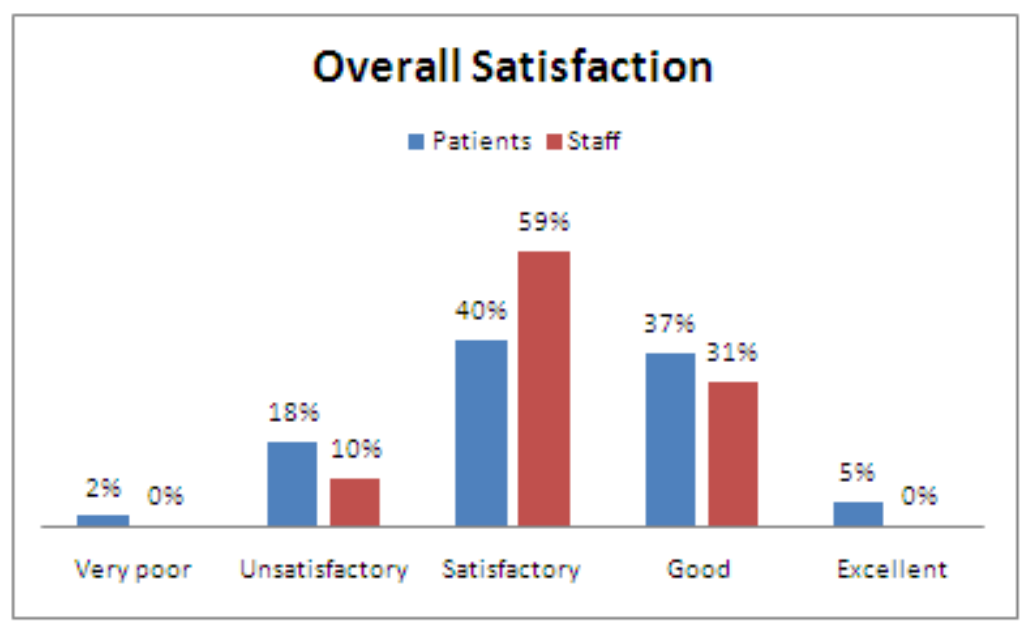

\section{References:}

[1]. Sofaer,S., and K.Firminger,(2005).Patient perceptions of the quality of health services. Annual Review Public Health; $26: 513-559$.

[2]. Ramsaran-Fowdar, R 2008, 'The relative importance of service dimensions in a healthcare setting ', International Journal of Health Care Quality Assurance, vol. 21 no. 1, 2008, pp.104-124.

[3]. Buttle, F. (1996). SERVQUAL: Review, critique, research agenda. Journal of Marketing; 30(1): 8-32

[4]. Parasuraman A., Berry L.L., and Zeithaml V.A., (1988), SERVQUAL: A multiple-item scale for measuring customer perceptions of service quality, Journal of Retailing,

[5]. Babakus, E. and Mangold, G.W. (1992), "Adapting the SERVQUAL scale to hospital services: an empirical investigation”, Health Services Research, Vol. 26 No.6, pp. 767-86. 